simply users of the devices provided by the manufacturer, it is of interest to have a brief look at the current state of this particular technology.

This volume continues to maintain the high standard of the previous volumes; its list of future attractions suggests that this trend might well continue.

Oliver S. Heavens

\section{THE LITERATURE OF SPECTROSCOPY}

Bibliographie des Spectres des Molécules Polyatomiques dans I'Ultraviolet à Vide

By A. Johannin-Gilles. Pp. iv + 166. (Brest: Faculté des Sciences de Brest, 1966.) n.p.

SpECTROSCOPISTs will be grateful for this guide to the literature on the vacuum ultra-violet of polyatomic molecules. This is a field which has developed considerably in recent years and has naturally played an important part in the development of the theory of molecular electronic structure. The references to work on this topic contained in this compilation are complete to 1964 and cover photoionization as well as spectroscopic studies.

W. C. PrICE

\section{ANGLO-GERMAN ELECTRONICS}

\section{Handbuch der Physik}

Herausgegeben von S. Flugge. (Encyclopedia of Physics.) Band 23: Elektrische Instrumente/Electrical Instruments. Bandherausgeber: A. E. Pannenborg. Pp. viii + 535. (Davon 354 Seiten in Englischer Sprache.) (Berlin and New York: Springer-Verlag, 1967.) 168 D.M.

THIs volume, with about half its articles written in English and half in German, covers a field rather different from what might be inferred from its title, for the moving coil instruments and bridge circuit of classical electrical measurement are not specifically dealt with. There are instead sections on low noise amplification, on messurements of electrical quantities at microwave frequencies, and the measurement of magnetic fields. There are also sections on the definitions and standardization of time and frequency, on the temperature measurement, and on the theory and practice of temperature regulation. There is also a section on the methods of recording data, both analogue and digital, and this is a particularly good example of a matter in which a comprehensive listing of the available methods is of great value to a person designing an experiment. It would be fair to say that the general level of the volume is that of a comprehensive and critical descriptive catalogue rather than that of fully detailed description. Adequate references to descriptions in books and papers are provided. There are two subject indexes, in England and in German, with a translation of each title into the other language.

H. BrADDICK

\section{RADIO COVERAGE}

\section{Radio Astronomy}

By John D. Kraus. With a Chapter on Radio-Telescope Receivers by M. E. Tiuri. Pp. $x+481$. (New York: MeGraw-Hill Book Company; Maidenhead: McGrawHill Publishing Company, Ltd., 1966.) $110 s$.

RADIO astronomy is old enough to have accumulated a large body of fundamentals but is still so rapidly changing as to deter potential authors from attempting to compass it. This book is welcome, therefore, as one of the very few which treats the subject more deeply than merely gaping at the infinite. It is also a good book. It aims to cover all aspects of radio astronomy. Fundamental definitions, electromagnetism and propagation of waves, radio telescopes and receivers and the astronomical results are discussed in turn. There is also a short account of basic astronomy so that the book is open to physicists and engineers with no knowledge of astronomy. This accessibility is gained by giving emphasis to the radio and much less to the astronomy.

The heart of the book comprises the chapters on radio telescopes and radio receivers which give detailed accounts of the different systems used and analyses of their operation and relative advantages in different circumstances. These are perhaps the best surveys of the field now available. If we ask what the problems are that these instruments solve and which systems are most suited for a particular kind of problem, then we are disappointed. In the space available the astronomical results can be scarcely more than a catalogue of the different types of objects that can be studied, and there is not much indication of how the design of instruments is related to the objects of study. This is a pity, but we must be pleased that half of radio astronomy has been covered so well.

J. E. BALDWIN

\section{SATELLITES OBSERVED}

\section{Observing Earth Satellites}

By Desmond King-Hele. Pp. $x+220$. (London: Macmillan and Co., Ltd., 1966.) 30s. net.

Looking at Earth satellites has become a popular sport among amateur astronomers, but it is still a somewhat esoteric activity. A person cannot hope to see satellites in the night sky as easily as he can find shooting stars in the right season. What Dr. King-Hele has done is to provide a guide to help those who wish to take the observations of satellites seriously and a much more general, and eminently readable, handbook for those who would know more about the ways in which Earth satellites (excluding the Moon) interact with the atmosphere of the Earth. The whole is put together gracefully, so that the book should be read with pleasure even by those whose attempts to see satellites are frustrated, for example, by a cloudy sky.

It seems that the most important piece of equipment for the satellite watcher is a deckchair. An overcoat is clearly another urgent need. The satellite watcher will first have placed the predicted path of the satellite he wants to find from a star atlas. A fow minutes before the arrival of the satellite, he picks out with binoculars a group of stars through which the satellite will pass. Dr. King-Hele reckons that a reasonably bright and well predicted satellite should be detected nine times out of ten. The surprise is that the timing of the passage of the satellite can be as accurate as 0.1 of a degree in right ascension and declination, chiefly by the skilful use of a stopwatch and a telephone speaking clock.

This is only half the story. Dr. King-Hele's book is full of detailed hints for watchers, no doubt clearly gathered from the deckchsir, with enough to suggest to all readers how the job might be done even more accurately, with fast sky cameras and with a clear picture of the great discoveries which have flowed from the use of Earth satellites in the past ten years. The way in which the observation of satellites has been used to determine more accurately the shape of the Earth, to make inferences about the interior of the Earth and to study the atmosphere a hundred miles and more above the Earth, is surely in many ways an unexpected consequence of the development of Earth satellites. Throughout the past decade, understanding of these matters has been accumulating steadily. Especially at the beginning but, with care, even now when the techniques of observation have become more sophisticated, unprofessional observers have been able to play an important part.

JoHN SPEnger 